\title{
Accuracy of reporting food energy intake: influence of ethnicity and body weight status in South African women
}

\author{
a Mchiza ZJ, PhD ' ${ }^{\mathrm{G}}$ Goedecke JH, PhD ${ }^{\mathrm{b}}$ Lambert EV, PhD \\ aKnowledge Systems, Nutrition Unit, Human Science Research Council, Cape Town, South Africa \\ ${ }^{\circ}$ UCT/MRC Research Unit for Exercise Science and Sports Medicine, Dept of Human Biology, Faculty of Health Sciences, University of Cape Town, South Africa \\ Correspondence to: Dr Zandile J Mchiza, e-mail: zmchiza@hsrc.ac.za \\ Keywords: South African women; misreporting; energy intake; body image; socioeconomic status
}

\section{Abstract}

The current study sought to identify characteristics that may be associated with the misreporting of food energy intake (EI) in urban South African women. A total of 198 women (61 black, 76 of mixed ancestry, 61 white) completed a quantified food frequency questionnaire, from which daily energy and macronutrient intake were calculated. Body composition (body mass index [BMI], percentage of body fat), body image (Feel-Ideal Difference index and Body Shape questions) and socio-economic status (SES) (household density and asset index) were also measured. Food $\mathrm{El}$ in relation to estimated basal metabolic rate ratio that was less than 1.05 represented under-reporting, whereas a ratio greater than 2.28 represented over-reporting. Results suggested that $26 \%$ of the participants under-reported, $64 \%$ adequately reported and $10 \%$ over-reported. Participants who under-reported had a higher BMI $(p<0.01)$ and higher percentage of body fat $(p<0.05)$ than those who adequately and over-reported. The majority of under-reporters were black (38\%) versus $21 \%$ under-reporters of mixed ancestry and $20 \%$ white under-reporters $(p<0.01)$. Eighty-three per cent of black under-reporters were obese. On the other hand, a majority $(63 \%)$ of overweight women of mixed ancestry and a majority $(50 \%)$ of white normal-weight women under-reported their food El. Under-reporters reported a lower intake of dietary fat $(p<0.01)$ and a higher intake of dietary protein $(p<0.01)$ than adequate or over-reporters. Food El reporting was not influenced by SES or body image. In conclusion, results suggest that food El reporting is influenced by body size, and may be ethnic-specific in South African women.

(P) Peer reviewed. (Submitted: 2009-09-24, Accepted 2010-04-25). ๑ SAJCN S Afr J Clin Nutr 2010;23(2): 84-89

\section{Introduction}

Obesity is a global problem. ${ }^{1}$ In South Africa, as in many other developing countries, adult women are the most vulnerable group, with a markedly higher prevalence of obesity than men. ${ }^{1,2}$ There is substantiated evidence suggesting obesity as a result of chronic positive energy balance in the form of food energy intake (El) that is higher than physical activity energy expenditure (PAEE). ${ }^{3}$ However, food El and PAEE (whether reported or measured) may be biased (under-reported, in particular) ${ }^{4,5}$ - to a greater extent in women than in men. ${ }^{6}$ What is of concern is that studies suggest that if food El-reporting bias is not evenly distributed in the population and affects certain nutrients, the interpretation of the relationship between diet and diseases in that population may be altered. ${ }^{5,7}$ As such, identifying the group or groups likely to under-report their food El and reasons for misreporting may help to understand the relationship between diet and obesity in South African women.

In addition to gender, ${ }^{6}$ international researchers have also highlighted factors such as age, ${ }^{8}$ socioeconomic status (SES) and education level, ${ }^{6,9,10}$ body composition, ${ }^{6,11}$ ethnicity or culture ${ }^{10,11}$ and social desirability ${ }^{9}$ as influences of food El misreporting. Bias in food El reporting can be measured by the ratio between reported food El and energy expenditure (EE). ${ }^{12} \mathrm{EE}$ may be estimated using basal metabolic rate $\left(\mathrm{BMR}_{\text {est }}\right)$, calculated using Schofield et al's ${ }^{13}$ equations, or measured $\left(\mathrm{BMR}_{\text {meas }}\right)$, using indirect calorimetry ${ }^{14}$ or doubly labelled water (DLW). ${ }^{15}$ However, the measurement of EE using indirect calorimetry or DLW in a large group of individuals is costly.

Various consultative groups and researchers have proposed guidelines for determining the El : BMR ratio. For example, in 1985, the Joint FAO/WHO/UNU Expert Consultation on Energy and Protein Requirements proposed that an El of $1.55 \times$ BMR was adequate for adults to sustain reasonable health and light activity. Moreover, Goldberg et al and others have recommended a range of Els from 1.35 to $1.67 \times$ BMR as a plausible ratio for adults in affluent societies to maintain health and lower levels of activity. ${ }^{12,15}$

Subsequently, Black ${ }^{16}$ reviewed the evidence supporting various proposed cut-off points in terms of the method used for measuring dietary intake, whether or not resting EE was measured or estimated, and the means by which physical activity levels were determined. In her analysis, she determined the specificity and sensitivity of various 
cut-off points in identifying under- and over-reporting. As such, she proposed a strategy that employed the $95 \%$ confidence intervals (Cls) around the El : BMR ratio under various conditions to reflect under- and over-reporting. The selection of criteria for classifying misreporting of food $\mathrm{El}$ is therefore informed by one's ability to estimate or measure resting and PAEE and the method used for collecting dietary intake data.

Only one study by Maclntyre et al ${ }^{17}$ previously identified food El misreporting in $43 \%$ of South Africans from a multi-ethnic sample of 178 men and women. However, the extent of misreporting and the factors associated with over- and under-reporting have not yet been studied. Therefore, the aim of the current study was to identify the extent and determinants of factors associated with the misreporting of food El in a sample of South African women of mixed ethnic origin.

\section{Methods and procedures}

\section{Study population}

This study was undertaken as part of a larger project in which diet, physical activity, knowledge, attitudes, beliefs and health behaviours in South African women and their daughters were evaluated, and published in part elsewhere, in which more detailed methodology is included. ${ }^{18}$

In brief, 15 primary schools in the Cape Town Metropole area were randomly selected and sampled on the basis of divergent SES. All girls (ages 9-12 years, grades 4-5) and their mothers were invited to participate in the study. Only the mothers were included in the current analysis and of the mothers who responded, all women who were involved in any weight change intervention strategy at the time of the study were excluded. As a result, the final sample of 198 women consisting of $31 \%$ black, $38 \%$ mixed-ancestry and $31 \%$ white women were included in this analysis. Ethics approval to undertake this study was obtained from the Western Cape Department of Education, as well as the Research Ethics Committee of the Faculty of Health Sciences at the University of Cape Town. All participants completed informed consent forms prior to participation in the study.

\section{Body composition, socioeconomic and psychosocial variables}

Body composition was assessed in the form of body mass index (BMI), calculated as weight (in kilograms) divided by the square of height (in metres) and percentage of body fat. Body weight was assessed in light clothing, without shoes, and recorded to the nearest $0.5 \mathrm{~kg}$ using a calibrated electronic scale (TANITA HD-309, Tanita Corporation of America Inc, USA). Height was measured without shoes to the nearest $0.5 \mathrm{~cm}$ using a calibrated odometer. Furthermore, to measure body fat stores, triceps, biceps, subscapular and suprailiac skinfold thicknesses were measured using calibrated Harpenden callipers, and recorded to the nearest $0.1 \mathrm{~mm}$. Thereafter the body fat percentage measurements were calculated using standard equations by Durnin and Womersely. ${ }^{19}$
Age, ethnic group, education level and SES (determined as asset index [which is the total number of appliances in one household out of a list of nine appliances] and household density [which is the total number of people residing in the same household for five or more days a week]) were also investigated. ${ }^{20}$

\section{Dietary intake}

In the current study, a quantified food frequency questionnaire (QFFQ) by Macintyre et al ${ }^{17}$ was employed. The QFFQ is a more appropriate, valid method that is more likely to give a true representative picture of the usual dietary intake of individuals over a period of time. It is also a more appropriate method used by researchers to link dietary intake to diseases. The QFFQ used in this regard was comprised of 122 food items obtained from local published studies on dietary intake by different ethnic groups of South Africa. The QFFQ is presented such that participants are able to choose the food items that they regularly consume, along with the quantity and frequency of consumption of these items, within the preceding month. Among other methods to validate the QFFQ, Macintyre et $\mathrm{al}^{17}$ compared it to the seven-day weighed food records (in 74 multi-ethnic adult South Africans between the ages of 15 and 65 years). Some of the results obtained by Macintyre et al ${ }^{17}$ were Spearman's rank correlations of 0.21 for fat, 0.35 for meat, 0.38 for fruit, 0.41 for vegetables as well as 0.56 for maize meal and added sugar.

The QFFQ was administered by trained registered dieticians. The field worker resource manual used for training the dieticians was prepared by the principal investigator for the current study. To aid participants in estimating their food portion sizes and food preparation methods, a food portion photograph book (FPPB) ${ }^{21}$ was used. The food El generated by the QFFQ was analysed using the South African Medical Research Council (MRC) Foodfinder 3 software program (WAMTechnology (C) and MRC RISD, 2001). The total energy (in $\mathrm{kJ}$ ) and macronutrient intake (in the form of the percentage of total energy derived from dietary fat, added sugar and dietary protein) generated from the analysis was then calculated to express average intake per day.

\section{Energy reporting status (EI : $B_{M R}$ )}

The reported El in relation to $\mathrm{BMR}_{\text {est }}\left(\mathrm{El}: \mathrm{BMR}_{\text {est }}\right.$ ratio) was calculated for each individual to determine the reporting status of the women. The BMR was estimated using Schofield standard equations. ${ }^{13}$ In the current study, an estimated blanketed physical activity level (for light activity) of 1.55 derived from the FAO/WHO/UNU in 1985 was used. This was based on the evidence from a South African study that suggested that urban women engage in light occupational activity. ${ }^{22}$ In this regard, the $95 \% \mathrm{Cl}$ were employed for the Goldberg et a ${ }^{12}$ and Black ${ }^{16}$ cut-off points with the sensitivity of 0.52 and specificity of 0.99 for under-reporting food El. As such, in the current study, any El : BMR ${ }_{\text {est }}$ value below a cut-off point of 1.05 represented underreporting. ${ }^{16}$ In addition, any El : $\mathrm{BMR}_{\text {est }}$ value above 2.28 represented over-reporting. ${ }^{16}$ All other participants were considered adequate reporters. ${ }^{16}$ 
Goldberg et al ${ }^{12}$ formulated these cut-off points by comparing food El to an individual's resting energy expenditure (measured using an objective measure such as DLW). Black ${ }^{16}$ also validated the food El results reported by Goldberg et al ${ }^{12}$ against 24-hour urinary nitrogen excretion and EE measured by DLW in British middle-aged women.

\section{Body image}

Body shape and size acceptance was assessed using the Body Shape Questionnaire (BSQ) by Cooper et $\mathrm{al}^{23}$ and the Feel-Ideal Difference (FID) index by Mciza et al. ${ }^{18}$ The BSQ is a 34 -item questionnaire that measures body shape concerns. A BSQ score $<1.23$ indicate lower body shape concerns, whereas a BSQ score $\geq 123$ indicated higher body shape concerns. Body size dissatisfaction was assessed using the FID index created by determining the difference in the number of silhouettes selected that best represented the participants' current appearance (determined as 'Feel'), and the one the participants thought was their 'Ideal' (the silhouettes they want to look like). A higher FID index score represents greater body size dissatisfaction, whereas a FID index score that approaches zero represents less body size dissatisfaction. The silhouettes used were derived from a set of nine silhouettes by Stunkard et $\mathrm{al}^{24}$ ranging from a very thin to very heavy body image.

\section{Statistical analysis}

All data were analysed using STATISTICA version 7.0 (StatSoft Inc, Tulsa, OK, USA). Values are presented as means \pm standard deviation. Chi-squared analysis was used to assess the frequency of food El-reporting status according to ethnicity and BMI groups and presented as a percentage. In addition, GraphPad Instat $t_{m}$ Dos Programme (Copyright (c) 1990-1994, Lambert M, University of Cape Town) was used to calculate Chi-squared test for trend of the adequate reporters' food El according to ethnic group and BMI categories. Two-way analysis of variance (ANOVA) was used to compare body composition, macronutrient intake, body image and SES between the ethnic and food El-reporting groups. Furthermore, advanced general linear model analysis was used to adjust for confounding factors of age and BMI on food El-reporting status between different ethnic groups.

\section{Results}

\section{Participants' characteristics}

Detailed characteristics of the main 204 sample are presented by Mciza et al. ${ }^{18}$ In brief, the average ages of the 198 women who participated in the current study were $42 \pm 5,38 \pm 5$ and $40 \pm 11$ years for the white, mixed-ancestry and black women respectively $(p=0.02)$. Furthermore, black women had significantly higher BMls $\left(33.6 \pm 7.8\right.$ vs $26.5 \pm 4.7$ and $25.4 \pm 4.1 \mathrm{~kg} / \mathrm{m}^{2}$, $\mathrm{p}<0.05)$ and body fat percentage $(34.5 \pm 6.3$ vs $32.2 \pm 4.8$ and $31.8 \pm 4.9 \%, p<0.05)$ than the mixed-ancestry and white women respectively. They also had significantly lower levels of education and also presented with significantly lower SES on the basis of asset index and household density than the other groups of women (all $p$ values $<0.001)$. In addition, when adjusting for age and $B M I$, white women scored significantly higher on the BSQ, indicating higher body shape concerns, than the mixed-ancestry and black women (86.7 \pm 24.1 vs $81.7 \pm 28.1$ and $80.8 \pm 35.0, p<0.05$, respectively). On the other hand, mixed-ancestry women scored significantly higher on the body size dissatisfaction (presented as FID index scores) than white and black women $(1.7 \pm 1.1$ vs $1.5 \pm 1.3$ and $1.2 \pm 2.2$, $p<0.05$, respectively).

\section{Misreporting of food energy intake}

Using the cut-off points of 1.05-2.28 for food El reporting, it was observed that overall, $26 \%$ of the women in this analysis underreported, $64 \%$ adequately reported and $10 \%$ over-reported their food El $(p<0.05)$. When comparing the food El-reporting status of the three ethnic groups of women, black women under-reported food El to a greater extent than mixed-ancestry and white women ( $45 \%$ vs $31 \%$ and $24 \%, p<0.01$, respectively).

Food El-reporting status according to BMl category and ethnicity is presented in figures $1 \mathrm{~A}$ and $1 \mathrm{~B}$. Figure $1 \mathrm{~A}$ shows that, of the $45 \%$ $(n=23)$ black women who under-reported food El, only $4 \%(n=1)$ were within the normal range of $\mathrm{BMI}, 13 \%(n=3)$ were overweight and $83 \%(n=19)$ were obese. Of the $31 \%(n=16)$ mixed-ancestry women who under-reported food El, $13 \%(n=2)$ were within the normal range of BMl, $63 \%(n=10)$ were overweight and $24 \%$

Figure 1: Frequency of (A) under-reporting and (B) adequate reporting of food El according to BMI category and ethnicity in South African women. Matching superscripts represent groups that are different from each other, $a(c 2=8.782, p<0.01)$; $b(c 2=10.667, p<0.01$ and $c 2=18.910, p<=0.001$, for black, mixed-ancestry and white, respectively)
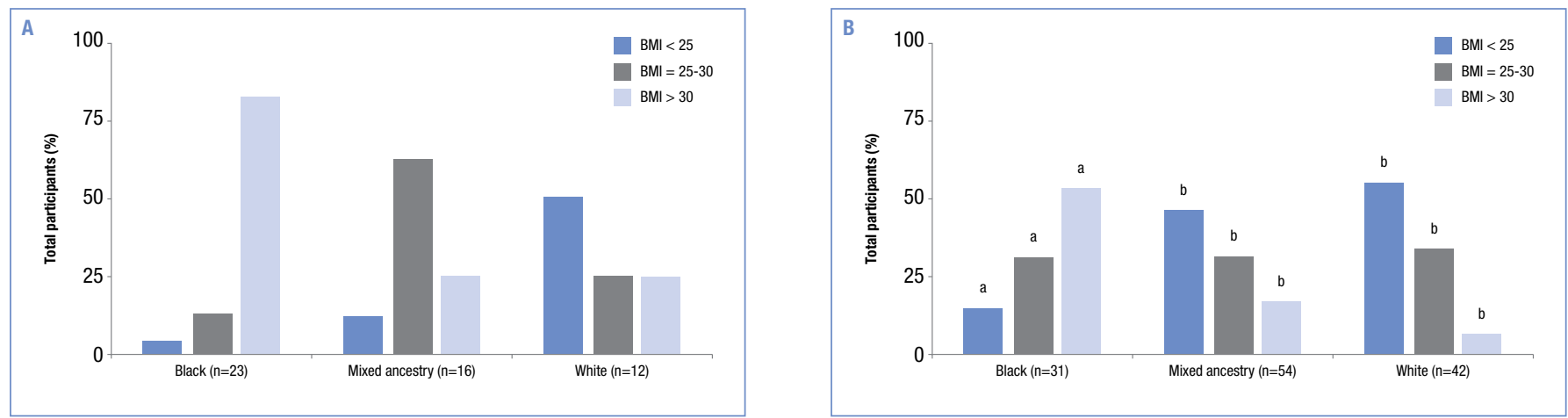
Table I: Characteristics of South African women according to ethnicity and food El-reporting status

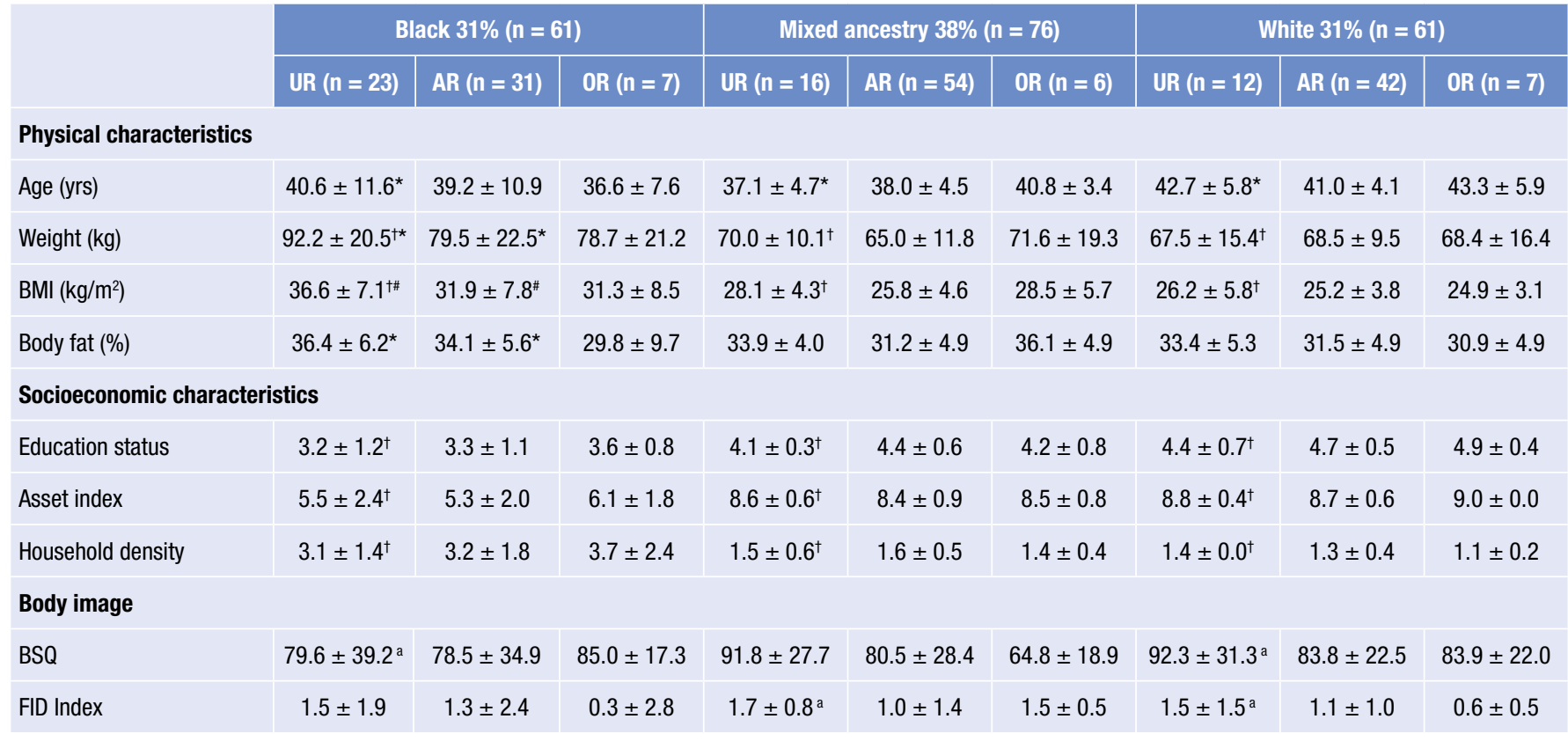

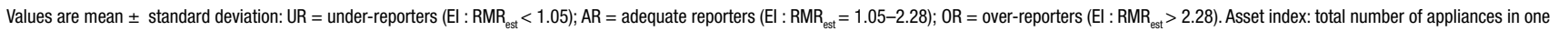
household out of nine; Household density: total number of people sleeping in the same household for five or more days a week; Education status: highest grade category passed. Matching superscripts represent groups that are significantly different from each other: ${ }^{*} p<0.05,{ }^{\dagger} p<0.001,{ }^{*} p<0.01$. After adjusting for $\mathbf{B M I}$ and age: ${ }^{a} p<0.05$

Table II: Reported macronutrient intake (in the form of percentage of total energy derived from dietary fat, protein and carbohydrates, as well as added sugar in grams) of South African women according to ethnicity and food El-reporting status

\begin{tabular}{|c|c|c|c|c|c|c|c|c|c|}
\hline & \multicolumn{3}{|c|}{ Black $31 \%(n=61)$} & \multicolumn{3}{|c|}{ Mixed ancestry $38 \%(n=76)$} & \multicolumn{3}{|c|}{ White $31 \%(n=61)$} \\
\hline & UR $(n=23)$ & $\operatorname{AR}(n=31)$ & $O R(n=7)$ & UR $(n=16)$ & $\operatorname{AR}(n=54)$ & $O R(n=6)$ & UR $(n=12)$ & $\operatorname{AR}(n=42)$ & $\mathrm{OR}(\mathrm{n}=7)$ \\
\hline Carbohydrates (\% TE) & $64.4 \pm 9.2^{\dagger}$ & $59.3 \pm 9.5$ & $57.9 \pm 6.5$ & $52.5 \pm 9.6^{\dagger}$ & $55.2 \pm 7.5$ & $53.9 \pm 9.0$ & $55.9 \pm 10.4^{\dagger}$ & $53.6 \pm 7.6$ & $53.4 \pm 13.0$ \\
\hline Fat (\% TE) & $22.9 \pm 8.6^{\dagger \#}$ & $28.4 \pm 8.3^{\#}$ & $29.3 \pm 7.7^{\#}$ & $30.9 \pm 7.6^{\dagger \#}$ & $31.7 \pm 6.9^{\#}$ & $34.7 \pm 9.6^{\#}$ & $29.7 \pm 8.5^{\dagger \#}$ & $32.8 \pm 6.6^{\#}$ & $35.0 \pm 12.2^{\#}$ \\
\hline Protein (\% TE) & $12.9 \pm 3.1^{\mathrm{a}}$ & $12.2 \pm 3.2^{\mathrm{a}}$ & $12.8 \pm 3.0^{\mathrm{a}}$ & $16.2 \pm 4.5^{\# \mathrm{a}}$ & $12.9 \pm 2.4^{\# a}$ & $11.3 \pm 2.6^{\# \mathrm{a}}$ & $13.6 \pm 3.4^{\mathrm{a}}$ & $13.1 \pm 3.0^{\mathrm{a}}$ & $11.2 \pm 2.6^{\mathrm{a}}$ \\
\hline Added sugar (g) & $15.5 \pm 6.9^{\ddagger}$ & $17.5 \pm 6.7^{\ddagger}$ & $19.7 \pm 5.5^{\ddagger}$ & $19.2 \pm 8.3^{\ddagger}$ & $16.0 \pm 7.2$ & $11.5 \pm 8.5^{\ddagger}$ & $20.6 \pm 12.8^{\ddagger}$ & $16.4 \pm 6.6$ & $12.5 \pm 7.4^{\ddagger}$ \\
\hline
\end{tabular}

Values presented as Mean in gramsrived from body fat percentage instead of percentage body fat. More over, we meant Values are mean \pm standard deviation: \% TE $=$ percentage of total energy; $g=$ grams $\mathrm{UR}=$ under-reporters $\left(E \mathrm{El}: \mathrm{RMR}_{\text {est }}<1.05\right) ; \mathrm{AR}=$ adequate reporters $\left(E \mathrm{El}: \mathrm{RMR}_{\text {est }}=1.05-2.28\right) ; 0 \mathrm{R}=$ over-reporters $\left(E \mathrm{El}: \mathrm{RMR}_{\text {est }}>2.28\right)$. Matching superscripts represent groups that are significantly different from each other:

${ }_{t} p<0.001$ : Black women reported higher carbohydrate intake and less fat intake than mixed-ancestry and white women.

$" \mathrm{p}<0.01$ : UR reported less fat intake than AR and OR in all ethnic groups. Furthermore, UR reported higher protein intake than AR and OR for the mixed-ancestry women.

${ }^{a} p<0.05$ : UR reported higher protein intake in black and white women only after adjusting for BMI and age of women.

${ }^{\ddagger} p<0.05$ : Black UR reported less added sugar intake than $A R$ and $O R$, whereas mixed-ancestry and white UR reported higher sugar intake than $0 R$.

$(n=4)$ were obese. Of the $24 \%(n=12)$ of white women who under-reported food El, $50 \%(n=6)$ were within the normal range of BMl, $25 \%(n=3)$ were overweight and $25 \%(n=3)$ were obese. A greater-than-expected proportion of mixed-ancestry women adequately reported food El, compared to their white and black counterparts $(71 \%[n=54]$ vs $69 \%[n=42]$ and $51 \%[n=31]$, $p<0.05$, respectively) (Figure $1 \mathrm{~B})$. The frequency of adequate reporters increased linearly with increasing BMl category in the black women (Chi-square $\left[\chi^{2}\right]=8.782$ and $p<0.01$ ), whereas the frequency of adequate reporters decreased linearly with increasing BMl category in the mixed-ancestry $\left(\chi^{2}=10.667\right.$ and $\left.p<0.01\right)$ and white women $\left(\chi^{2}=18.910\right.$ and $\left.p<0.001\right)$. There were no significant differences in over-reporting between ethnic groups across BMI categories.
The characteristics of the women according to ethnicity and food El-reporting status are presented in Table I. Those women who under-reported food El were significantly heavier $(p<0.05)$, had a higher BMI $(p<0.01)$ and percentage of body fat $(p<0.05)$ than those that adequately reported food El. Although black women were significantly heavier in terms of weight $(p<0.001)$ and had higher BMls $(p<0.001)$ than the mixed-ancestry and white women, no significant ethnic differences in food El reporting were observed $(p$ $=0.20$ ). Despite the fact that black women presented with lower education levels and lower SES, these characteristics did not influence food El-reporting status. Similarly, food El-reporting status was not influenced by body image (characterised by FID index and BSQ scores). 
Reported macronutrient intake according to ethnicity and food El-reporting status is presented in Table II. Irrespective of food El-reporting status, black women had higher carbohydrate intake and less dietary fat intake than the other groups of women (all $p$ values $<0.001$ ). These results were independent of age and BMI. Significa nt ethnic differences in reported protein intake were observed only after adjusting for the age and BMl of women. Furthermore, underreporters in all ethnic groups reported less dietary fat and a higher dietary protein intake compared to the adequate and over-reporters (both $p$ values $<0.01$ ). There was a significant interaction effect for ethnicity and food El-reporting status for reported added sugar intake $(p<0.05)$. In this regard, black women reported a consistently higher added sugar intake for both adequate and over-reporters than the other groups of women. Black under-reporters also reported less added sugar intake than black adequate and over-reporters. White and mixed-ancestry under-reporters, on the other hand, reported a significantly higher added sugar intake compared to the white and mixed-ancestry over-reporters. These significant differences disappeared after adjusting for the age and BMI of women.

\section{Discussion}

The main aim of this study was to identify characteristics in urban South African women that may be associated with the misreporting of food El, including ethnicity, SES, body composition (BMl and body fat percentage), body image and macronutrient intake. The main findings of this study were that $26 \%$ of the women under-reported their food El, with a greater proportion of under-reporters being black and obese. In contrast, more overweight women of mixed ancestry and more normal weight white women under-reported food El. Under-reporters also reported less dietary fat intake and higher dietary protein intake than the adequate and over-reporters.

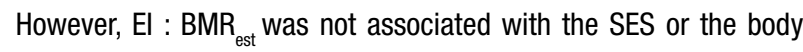
image of women.

These findings highlight a significant problem in terms of estimating food El, as $26 \%$ of the women reported implausible food El. This percentage is higher than that reported in a similar study conducted in another developing country. ${ }^{11}$ For example, only $10 \%$ of the Egyptian women in Harrison's study under-reported their food El. However, the proportion of under-reporters in the current study is closer to that found in one-third of American women. ${ }^{11}$ As such, the role of dietary factors in the aetiology of obesity in South African studies should be interpreted with caution, bearing in mind the influence of this food El-reporting bias. However, obtaining more knowledge of the factors that influence food El reporting in South Africa will help with the design of better dietary assessment instruments and possibly of studies evaluating diet-disease relationships, as proposed by Johansson et al. ${ }^{5}$

In the current study, ethnic background appeared to play a role in the bias of food El reporting, in that black women were more likely to under-report their food El than mixed-ancestry and white women.
An explanation for these findings may be that the majority of black South African women in the current study were obese compared to other ethnic groups of women. There is well-established international evidence suggesting that obese women are more likely to underreport their food El than lighter women. ${ }^{9}$ As such, it may seem as if under-reporting is not ethnic- or culture-bound, but only relates to body composition. However, the ethnic differences in food El reporting have also been observed in other similar international studies. ${ }^{10,11}$ The results of the current study regarding ethnic differences in food El reporting, however, contrast with those of Kimm et al, ${ }^{11}$ who found that white adolescent American girls under-reported their food EI to a greater extent than their black counterparts. Differences in the findings of Kimm et al's ${ }^{11}$ study and the findings of the current study may relate to the age difference between the two study groups.

However, both the current study and Kimm et al's ${ }^{11}$ study highlight that $\mathrm{BMI}$ is one of the most consistent factors in predicting food El under-reporting in women of different ethnic origins. For example, in the current study, only $4 \%$ of black women in the lowest BMI category under-reported food El compared to $13 \%$ of mixed-ancestry and $50 \%$ of white women. Similarly, Kimm et al ${ }^{11}$ found that black girls in the highest tertile of BMI under-reported food El to a greater extent than white girls, while within the lowest BMI tertile, black girls under-reported food El somewhat less than white girls.

The differences in the BMl level at which black, mixed-ancestry and white adult women in the current study under-reported their food El might be explained, in part, by ethnic differences in body image discussed by Mciza et al. ${ }^{18}$ In this study, results suggested that black adult women experienced dissatisfaction about their body size status at a higher level of $\mathrm{BMl}\left(\mathrm{BMl}>30 \mathrm{~kg} / \mathrm{m}^{2}\right)$ than the mixedancestry women, who experienced body size dissatisfaction even if they were somewhat overweight $\left(\mathrm{BMl}>25 \mathrm{~kg} / \mathrm{m}^{2}\right)$ and the white women, who experienced body size dissatisfaction even if they were not overweight at all $\left(\mathrm{BMl}<25 \mathrm{~kg} / \mathrm{m}^{2}\right)$. To our surprise, in the current study, body image parameters such as body size dissatisfaction (presented as greater FID index scores) and body shape concerns (presented as greater BSQ scores) were not specifically associated with food El-reporting status.

Previous studies have also suggested that social class is an important risk factor for under-reporting. ${ }^{5,11}$ In the current study, the majority of black women were of a lower social class (based on educational level, household density and asset index scores) than the majority of mixed-ancestry and white women. However, in the current study, educational level and SES did not influence food El reporting. Similarly, Harrison et a $1{ }^{10}$ observed no relationship between food Elreporting status and formal education in Egyptian women.

Misreporting in the current study did not only influence total food El, but also biased the reporting of macronutrient intake in that under-reporters reported less dietary fat and a higher dietary protein intake than adequate and over-reporters. Similar results have been reported in other international studies. ${ }^{4,5}$ In some of these studies, 
guilt associated with the consumption of food items emphasised in dietary modification interventions as unhealthy - fat in particular have also been regarded as the drivers of under-reporting this food item in women with higher BMls. From the current data, researchers were not able to ascertain whether guilt influenced macronutrient reporting. However, all participants who participated in dietary modification interventions directed at losing weight were excluded from the current analysis, reducing the likelihood of this factor confounding the results. However, future research should explore whether guilt influences macronutrient reporting in the South African context, and whether there are any cultural differences that may also be driven by social norms regarding this aspect.

In conclusion, the current study identified a significant group of women who misreported their food El, based on the cut-off range of 1.05 to $2.28 \mathrm{El}: \mathrm{BMR}_{\text {est }}$. Food El under-reporting in these women was influenced by body size status and differed according to ethnicity. Furthermore, food El reporting influenced macronutrient reporting. As such, studies designed to explore the relationship between dietary intake and obesity might be confounded by the bias in food El and macronutrient reporting, compromising interventions aimed at preventing and managing obesity in South African women.

\section{Disclosure}

This research was funded by the Nestlé Foundation. We also give special thanks to the MRC of South Africa, Unit of Chronic Diseases of Lifestyle, the South African Department of Science and Technology and the National Research Foundation for the primary investigator's scholarship.

\section{Acknowledgements}

Gratitude is extended to all the principals, parents and learners in the Cape Town Metropole primary schools in which the study was conducted. Moreover, the assistance of Nasreen Jaffer, Lauren Hill, Madalane Carsten and Alicia Hess in the process of data collection and data entry is appreciated. Last but not least, thanks to the MRC/ UCT Unit for Exercise Science and Sports Medicine, Department of Human Biology, at the University of Cape Town, for supplying a conducive environment for this research.

\section{References}

1. Ono T, Guthold R, Strong K. WHO Global Comparable Estimates. 2005 Accessed [2010 May 27]. Available from http://www.who.int/infobase IBRRef:199999

2. Puoane $T$, Steyn $K$, Bradshaw D, et al. Obesity in South Africa: The South African demographic and health survey. Obes Res. 2002;10(10):1038-1048.

3. Griera JL, Manzanares JM, Barbany M, Contreras J, Amigó P, Salas-Salvadó J. Physical activity, energy balance and obesity. Public Health Nutr. 2007;10(10A):1194-1199

4. Cook A, Pryer J, Shetty P. The problem of accuracy in dietary surveys: Analysis of the over 65 UK National Diet and Nutrition Survey. J Epidemiol Community Health 2000;54(8):611-616.

5. Johansson L, Solvoll K, Bjorneboe GE, Drevon CA. Under- and overreporting of energy intake related to weight status and lifestyle in a nationwide sample. Am J Clin Nutr. 1998;68(2):266-274.

6. Amirkalali B, Najafi M, Ataie-Jafari A, Hosseini S, Heshmat R. Under- and overreporting of energy in a group of candidates for CABG surgery and its association with some anthropometric and sociodemographic factors, Tehran, Iran. Vascular Health and Risk Management 2008;4(5):1115-1120.

7. Beaton GH. Approaches to analysis of dietary data: Relationship between planned analyses and choice methodology. Am J Clin Nutr. 1994;59(suppl):253S-261S

8. Bandini LG, Cyr H, Must A, Dietz WH. Validity of reported energy intake in pre-adolescent girls. Am J Clin Nutr. 1997;65:1138S-1141S

9. Horner NK, Patterson RE, Neuhouser ML, Lampe JW, Beresford SA, Prentice RL. Participant characteristics associated with errors in self-reported energy intake from the Women's Health Initiative food-frequency questionnaire. Am J Clin Nutr. 2002;6(4):766-773.

10. Harrison GG, Galal OM, Ibrahim N, et al. Underreporting of food intake by dietary recall is not universal: A comparison of data from Egyptian and American women. J Nutr. 2000;130:2049-2054.

11. Kimm SY, Glynn NW, Obarzanek E, Aston CE, Daniels SR. Racial differences in correlates of misreporting of energy intake in adolescent females. Obesity (Silver Spring) 2006;14(1):156-164.

12. Goldberg GR, Black AE, Jebb SA, et al. Critical evaluation of energy intake data using fundamenta principles of energy physiology. 1: Derivation of cut-off values to identify under-recording. Eur J Clin Nutr. 1991;45:569-581.

13. Schofield WN, Schofield C, James WPT. Basal metabolic rate. Human Nutrition: Clinical Nutrition 1985;39C(Suppl.1):1-96.

14. Schoeller DA. Recent advances from application of doubly labelled water to measurement of human energy expenditure. J Nutr. 1999;129:1765-1768.

15. Coward WA, Cole, TJ. Determination of optimum dosing ratios. In: Prentice AM, editor. The doublylabelled water method for measuring energy expenditure. Vienna: IAEA, 1990; p. 294-301.

16. Black AE, Welch AA, Bingham SA. Validation of dietary intakes measured by diet history against $24 \mathrm{~h}$ urinary nitrogen excretion and energy expenditure measured by the doubly-labelled water method in middle-aged women. Br J Nutr. 2000;83(4):341-354.

17. MacIntyre UE, Venter CS, Vorster HH. A culture-sensitive quantitative food frequency questionnaire used in an African population. 1: Development and reproducibility. Public Health Nutr. 2001;4(1):53-62.

18. Mciza Z, Goedecke JH, Steyn NP, et al. Development and validation of instruments measuring body image and body weight dissatisfaction in South African mothers and their daughters. Public Health Nutr. 2005;8(5):509-519.

19. Durnin JV, Womersley J. Total body fat, calculated from body density and its relationship to skinfold thickness in 571 people aged 12-72 years. Proc Nutr Soc 1973;32(1):45A.

20. Moser C, Felton A. The construction of an asset index: Measuring asset index accumulation in Ecuador Global economy and development. Working Paper 87. Mass: Chronic Poverty Research Centre, The Brooking Institution; July 2007.

21. Venter CS, MacIntyre UE, Vorster HH. The development and testing of a food portion photograph book fuse in an African population. Journal of Human Nutrition \& Dietetics 2000;13(3):205-218.

22. Kruger HS, Venter C, Vorster HH, Margetts BM. Physical inactivity is the major determinant of obesity in black women in the North West province, South Africa: The THUSA Study. Nutrition 2002;18:422-427.

23. Cooper PJ, Taylor MJ, Cooper Z, Fairburn CG. The development and validation of the Body Shape Questionnaire. International Journal of Eating Disorders 1987;6(4):485-494.

24. Stunkard AJ, Sorensen T, Schulsinger F. Use of the Danish Adoption Register for the study of obesity and thinness. Res Publ Assoc Res Nerv Ment Dis. 1983;60:115-20. 